

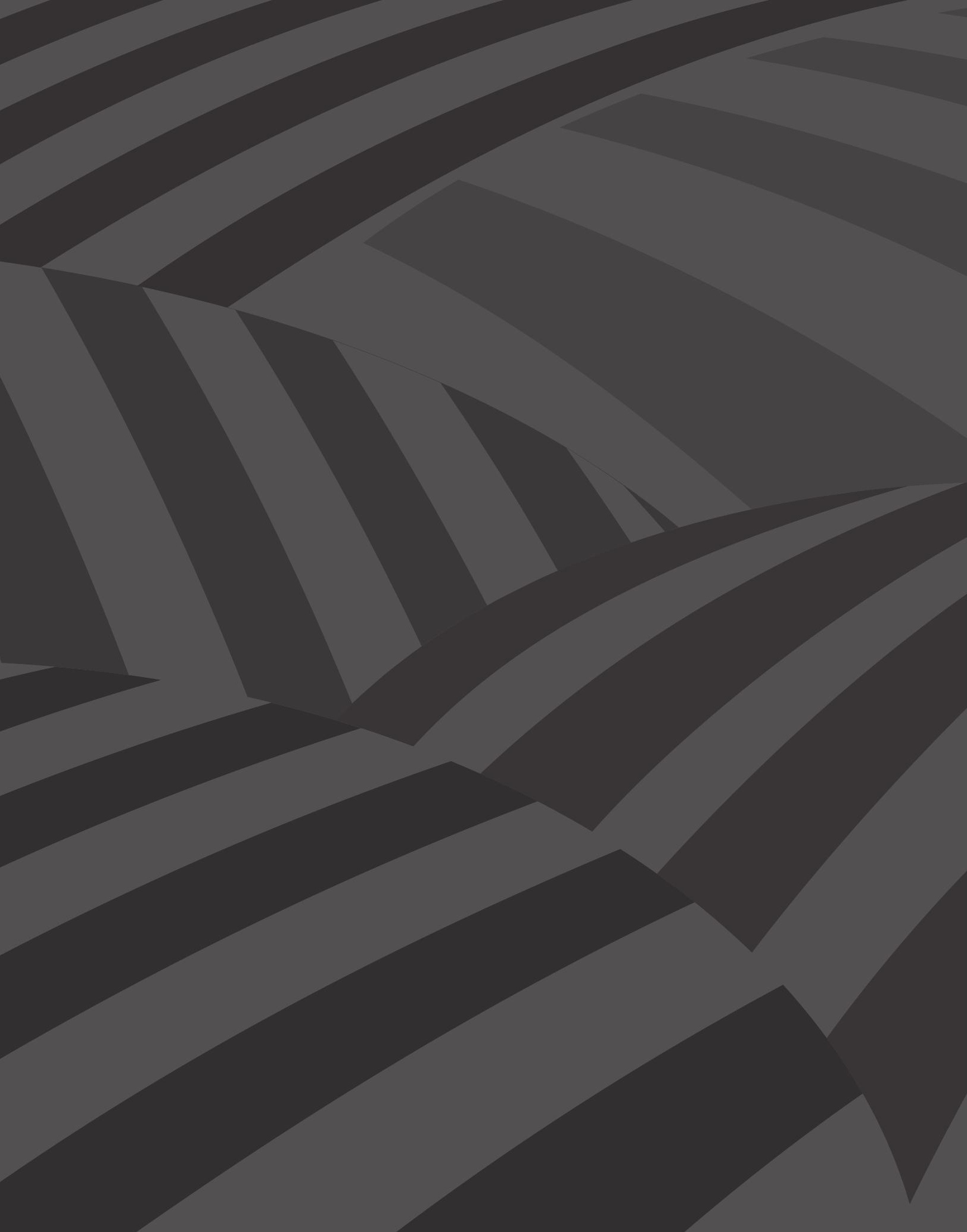




\section{Zonificación ambiental participativa: una oportunidad para la conservación de la naturaleza y su planificación en el posacuerdo}

Por Sergio Borda León* y Jhon Alexander Giraldo Vargas**

Resumen: En el presente artículo se analizan los antecedentes de la zonificación ambiental participativa (ZAP), teniendo como principal pretensión aportar elementos conceptuales y metodológicos para una planeación incluyente. La ZAP es un instrumento definido en el marco de la construcción del plan de zonificación ambiental propuesto en el Acuerdo Final para la Terminación del Conflicto y la Construcción de una Paz Estable y Duradera, concretamente en el punto 1. Hacia un nuevo campo colombiano: Reforma Rural Integral. Allí se presenta como una herramienta angular e innovadora que puede transformar los ejercicios de planificación ambiental, a partir de la participación efectiva de las comunidades locales, y contribuir a la construcción de apuestas territoriales para la identificación de las áreas de especial interés ambiental, el cierre de la frontera agropecuaria y la búsqueda de alternativas equilibradas para las comunidades locales en las zonas rurales.

Palabras clave: Planificación territorial, zonificación, áreas de especial interés ambiental, frontera agropecuaria, conservación ambiental.

\section{Participatory Environmental Zoning: An Opportunity for Environmental Conservation and its Planning in the Post-Agreement}

Abstract: This article analyzes the background of Participatory Environmental Zoning (ZAP), with the main intention of providing conceptual and methodological elements for inclusive planning. The ZAP understood as an instrument defined in the framework of the construction of the environmental zoning plan proposed in the peace effort, in the first point called Integral Rural Reform, as an angular and innovative tool that could transform environmental planning exercises, based in

* Consultor. Ingeniero agrícola. MSC en territorio, conflicto y cultura. bboorrddaa@ gmail.com.

** Consultor. Ingeniero ambiental, especialista en evaluación ambiental de proyectos, MSC en tecnología ambiental. jagiraldov@gmail.com 
the effective participation of local communities and contributing to the construction of territorial resources for the identification of areas of special environmental interest, the agricultural frontier and the search for balanced alternatives for local communities in rural areas.

Key words: Land planning, zoning, areas of special environmental interest, agricultural frontier, environmental conservation.

Cómo citar este artículo: Borda León, Sergio y Giraldo Vargas, Jhon Alexander (2020). Zonificación ambiental participativa: una oportunidad para la conservación de la naturaleza y su planificación en el posacuerdo. Revista Controversia, 214, 125-165.

Fecha de recepción: 1 de octubre de 2019

Fecha de aprobación: 18 de noviembre de 2019

\section{Introducción}

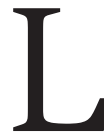

a zonificación ambiental participativa (ZAP) puede definirse como un proceso de planeación territorial alternativo, integral y dinámico, que incorpora el componente sociocultural tanto a nivel espacial como programático y construye estrategias de conservación comunitaria a partir de su integración, lo que permite propiciar el empoderamiento de las comunidades como sujetos de conocimiento y decisión para la búsqueda de soluciones a los conflictos socioambientales.

En este marco conceptual, la propuesta para la construcción de una ruta metodológica para la elaboración de la zAP busca que las organizaciones de base y las comunidades de los grupos diferenciales converjan con la institucionalidad, en propuestas e iniciativas comunes y concertadas para el desarrollo del Plan de Zonificación Ambiental, a partir de una efectiva y vinculante participación para la toma de decisiones soportadas en los principios de uso sostenible de la biodiversidad, los derechos del campesinado, la soberanía alimentaria, el diálogo de saberes y la justicia ambiental (Borda, Giraldo, Sanchez y Torres, 2018). 
A partir del contexto señalado, el artículo se estructura en cinco apartados. En el primero se presenta una descripción general del concepto de ZAP y sus objetivos; en el segundo se abordan los antecedentes inmediatos a partir de su relación con otros instrumentos que complementan su desarrollo, y con experiencias determinantes que orientaron su formulación e implementación. Un tercer apartado explica la visión de la participación como eje estructural de la planeación propuesta en la ruta metodológica para la zonificación ambiental y su relación intrínseca con los propósitos del Acuerdo de Paz. El cuarto enuncia los enfoques, las fases e instrumentos propuestos en la ruta metodológica para la zonificación ambiental participativa en zonas de reserva campesina, analizando los aspectos particulares con relación a otros ejercicios de ordenamiento ambiental. Finalmente, se exponen una serie de reflexiones desde el carácter transformador que tiene la ZAP en la manera de construir territorialidades, los importantes aportes metodológicos que hace al ordenamiento ambiental y territorial, pero, sobre todo, lo que representa para una paz estable y duradera en nuestros territorios.

\section{Aproximaciones conceptuales de la zonificación ambiental participativa}

Luego de un conflicto de más de medio siglo en el que se encontraba sumido el país, y en el que los territorios rurales han sido los más afectados, en el 2016 se firma el Acuerdo Final para la Terminación del Conflicto y la Construcción de una Paz Estable y Duradera entre el Gobierno Nacional y las FARC-EP (en adelante Acuerdo de Paz). Este propone diferentes estrategias para la transformación social y plantea la necesidad de un diálogo amplio para vislumbrar soluciones a las causas estructurales del conflicto, entre ellas la relacionada con la lucha histórica por la tierra que han librado actores sociales subalternos como las comunidades indígenas, afros, campesinas, raizales y palenqueras (Fajardo, 2002), poblaciones que han sido mayormente afectadas por el fenómeno del desplazamiento y el despojo de sus territorios, viéndose 
obligadas a relocalizarse y colonizar nuevas zonas del territorio sobre las áreas ambientales.

Reconociendo el importante papel del campo y su ruralidad, el Acuerdo de Paz desarrolla este aspecto mayormente en el punto relativo a la Reforma Rural Integral (punto 1), el cual busca la transformación estructural del campo con promoción amplia de la participación, mediante estrategias que, por un lado, modifiquen la estructura de la tenencia de la tierra permitiendo la restitución, formalización y distribución equitativa de esta, así como el acceso progresivo a ella por parte de las comunidades rurales; y por otro lado, el uso adecuado de la tierra de acuerdo con sus características biofísicas y socioeconómicas, para garantizar un ordenamiento socio-ambiental sostenible (Gobierno Nacional de Colombia y FARC-EP, 2016). Para garantizar el adecuado manejo de la tierra se ponen en discusión las situaciones relacionadas con el aprovechamiento y ocupación de las áreas de importancia y fragilidad ambiental, así como las zonas de expansión de la frontera agropecuaria.

En este contexto, el Acuerdo de Paz, para promover el uso adecuado del suelo y la resolución de conflictos, establece instrumentos alternativos que involucran el diálogo y la participación amplia de las comunidades locales, como actores centrales en el ordenamiento del territorio. Uno de estos instrumentos se encuentra plasmado en el apartado 1.1.10 referente al cierre de la frontera agrícola y protección de zonas de reserva, y corresponde al denominado Plan de Zonificación Ambiental (PZA), el cual busca cumplir tres grandes objetivos: i) promover el cierre de la frontera agropecuaria, ii) identificar y ampliar el inventario de las áreas de especial interés ambiental (AEIA) y iii) la generación de alternativas equilibradas para las comunidades locales que las colindan o las ocupan (Gobierno Nacional de Colombia y FARC-EP, 2016).

De acuerdo con lo anterior, en el marco de la implementación de dicho plan se realizaron varios pilotos en diferentes zonas del país, en los que se incorporó la participación activa de las comunidades locales en ejerci- 
cios de planificación y ordenamiento de la denominada zonificación ambiental participativa (MADS, 2019a). En principio, es importante abordar el término zonificación, el cual puede definirse como un proceso de segregación, división o parcelamiento, de manera regular o irregular, de un área seleccionada, en subzonas o áreas de menor tamaño, donde todas o parte de sus características o atributos son similares y tienen un alto grado de similitud, para un propósito específico (Jiménez, 1995; Ponce, 1998). Dicho propósito, viene dado por la expresión que la acompaña, en este caso "lo ambiental". La zonificación ambiental puede definirse entonces como la integración de aspectos ecológicos y socioeconómicos relevantes, para la categorización de áreas con similares limitaciones y potencialidades, haciendo énfasis en la conservación de los espacios ecosistémicos y de uso por parte del ser humano (Solano, 2017).

Es posible inferir, por tanto, que dicho proceso de zonificación implica, en sí, un ejercicio de planificación y ordenamiento abordado desde el paradigma del desarrollo sostenible, el cual debe estar fundamentado en una forma de vida en la que la población humana conviva con el medio natural, de una manera tal que sus necesidades sean satisfechas a partir de un aprovechamiento sostenible de los beneficios ecosistémicos (Domínguez, 2008; Villegas, Cifuentes, Contreras y Fernández, 2015); por tanto, el ejercicio de zonificación se circunscribe a un instrumento en lo denominado como ordenamiento territorial.

En la praxis, las diferentes metodologías establecidas para aplicar el proceso de zonificación ambiental presentan algunas características comunes en su determinación de áreas; las categorías se establecen con igual o similar potencial natural y aptitud de uso, basadas en un inventario de los componentes del ecosistema (donde predominan las variables biofísicas), ponderados y relacionados entre sí, y cuyo resultado son áreas equipotenciales a las que se condicionan los diferentes usos humanos (Montoya, 2011). 
Esta visión genera por tanto un sesgo, al establecer las condiciones de la naturaleza como inamovibles o estables y desconocer que dichos ejercicios son abordados sobre un territorio, entendido este como una forma espacial construida, producto de la totalidad de las interrelaciones entre un tipo de sociedad determinada y un tipo de ambiente o ambientes específicos durante un periodo de tiempo (Estrada, Ordoñez y Sánchez, 2013). En tanto, la intervención del ser humano y la producción del espacio construyen segundas naturalezas o nuevos entornos creados, en los cuales el ser humano al igual que los demás organismos transforman el ecosistema de acuerdo a sus dinámicas y están siempre en proceso de adaptación a los ecosistemas que ellos mismos originan (Hearvy, 2018). Por consiguiente, no puede considerarse la actividad humana fuera de los ecosistemas; esto quiere decir, a su vez, que un territorio no puede organizarse sobre la base de una supuesta homogeneidad ambiental y debe ser estudiado en toda la complejidad de sus transformaciones (Domínguez, 2008). De ahí la importancia de atravesar dichos procesos con la producción social del territorio que realizan los actores subalternos (Raffestin, 2011), como las comunidades campesinas, afros, indígenas, raizales y palenqueras.

De lo anterior se infiere que no existe una única propuesta de planificación para el territorio y que persisten varios enfoques, entre los cuales podemos mencionar: "el normativo, el técnico-oficial-occidental, el tradicional indígena” (Wilche Chaux, 2007). En este sentido, y con el fin de incorporar otros enfoques diferentes al técnico-oficial que persiste en general en este tipo de procesos, la ZAP busca romper con ellos en la planificación desde un cambio en el paradigma de la objetividad y la causalidad, como única forma de generar validez sobre un conocimiento (Ortiz, 2013) que permita transitar hacia modelos desde la subjetividad y las formas experienciales de construcción colectiva de conocimiento igualmente válido.

En la misma línea discursiva la ZAP, de acuerdo con lo planteado por Borda et al. (2018), puede entenderse como un proceso alternativo, integral 
y dinámico de planificación del territorio, basado en un ejercicio de gobernanza desde los actores subalternos - comunidades campesinas, indígenas y negras - con sus respectivas territorialidades, hacia las instituciones del Estado, contemplando sus formas de ocupación y apropiación del territorio, propiciando un diálogo de saberes amplio y participativo.

En dicho diálogo las comunidades no solo tienen poder de decisión, sino que construyen colectivamente propuestas de planificación de su territorio y la naturaleza, desde aspectos como: I) socioculturales tanto a nivel espacial como programático, permitiendo actualizar y ampliar el inventario de áreas de especial interés ambiental (AEIA); II) reuniendo modelos de conservación comunitarios y alternativos, asumiendo a las comunidades locales, su cultura y conocimiento tradicional como parte de la biodiversidad, sin desligar las áreas ambientales, ni los entornos creados a partir de la actividad humana. Teniendo como consecuencia, la construcción de un manejo integral que, respeta la ocupación histórica y ancestral de las comunidades arraigadas, rompiendo los viejos estigmas asociados a la destrucción ambiental y, en su lugar, proporciona el empoderamiento de las comunidades como sujetos de conservación para la búsqueda de soluciones a los conflictos socioambientales, el buen vivir de las comunidades y el cierre de la frontera agropecuaria, a través de la estabilización de la población (Borda et al., 2018).

De igual manera, para desarrollar los elementos u objetivos más relevantes de la ZAP, tales como el cierre de la frontera agropecuaria, la identificación de AEIA de acuerdo con los elementos conceptuales y teóricos que la componen, así como de los antecedentes abordados con mayor detalle en apartados posteriores, es posible establecer que dichos objetivos poseen un espectro mucho más amplio e integral de lo tratado en el Acuerdo de Paz. En razón a esto, en la tabla 1 se sintetizan algunas de sus características más importantes. 
Tabla 1. Descripción conceptual de los objetivos de la ZAP

\begin{tabular}{|c|c|c|}
\hline $\begin{array}{c}\text { Cierre de la frontera } \\
\text { agropecuaria }\end{array}$ & $\begin{array}{c}\text { Identificación de } \\
\text { AEIA }\end{array}$ & $\begin{array}{c}\text { Alternativas } \\
\text { equilibradas para las } \\
\text { comunidades }\end{array}$ \\
\hline $\begin{array}{l}\text { - Es un proceso paulatino e } \\
\text { integral para desacelerar } \\
\text { el proceso de expansión } \\
\text { de las actividades agrope- } \\
\text { cuarias. } \\
\text { - Implica la estabilización } \\
\text { de la población en las } \\
\text { zonas de colonización } \\
\text { activas, con garantía de } \\
\text { derechos. } \\
\text { - Es necesario analizar el } \\
\text { modelo de ocupación del } \\
\text { territorio, sus caracterís- } \\
\text { ticas y dinámicas econó- } \\
\text { micas, políticas, socio- } \\
\text { culturales, ambientales e } \\
\text { históricas. } \\
\text { - Su consecución dependerá } \\
\text { del adecuado ordenamien- } \\
\text { to productivo, social y am- } \\
\text { biental del territorio, con } \\
\text { criterios de justicia social } \\
\text { y ambiental. } \\
\text { - Conlleva la búsqueda de } \\
\text { soluciones de fondo a los } \\
\text { conflictos socioambienta- } \\
\text { les, para la mejora de las } \\
\text { relaciones socioecosis- } \\
\text { témicas y el flujo de sus } \\
\text { beneficios a la población. }\end{array}$ & $\begin{array}{l}\text { - Se centra principalmente } \\
\text { en torno al uso, manejo } \\
\text { y conservación de los re- } \\
\text { cursos estratégicos como } \\
\text { fuentes de vida, a saber; } \\
\text { las zonas de reserva fores- } \\
\text { tal, zonas de alta bio- } \\
\text { diversidad, ecosistemas } \\
\text { frágiles y estratégicos, } \\
\text { cuencas, páramos, hume- } \\
\text { dales y demás fuentes y } \\
\text { recursos hídricos, con mi- } \\
\text { ras a proteger la biodiver- } \\
\text { sidad y el derecho progre- } \\
\text { sivo a ellos, por parte de la } \\
\text { población, propiciando su } \\
\text { uso racional. } \\
\text { Se parte del hecho de que } \\
\text { son territorios interconec- } \\
\text { tados en los que existen } \\
\text { relaciones socioecosisté- } \\
\text { micas que deben mejorar- } \\
\text { se y mantenerse. } \\
\text { Comprende a su vez todas } \\
\text { las áreas de importancia } \\
\text { ambiental, cultural, pai- } \\
\text { sajística, espiritual y de } \\
\text { recreación ambiental, des- } \\
\text { de la visión de las comu- } \\
\text { nidades locales, haciendo } \\
\text { parte integrante de la bio- } \\
\text { diversidad a conservar. } \\
\text { Las comunidades loca- } \\
\text { les deben considerarse } \\
\text { como sujetos activos de } \\
\text { conservación y su empo- } \\
\text { deramiento garantiza su } \\
\text { existencia en el territorio. }\end{array}$ & $\begin{array}{l}\text { - Generar condiciones equi- } \\
\text { tativas frente a la distri- } \\
\text { bución de obligaciones y } \\
\text { beneficios de los socioeco- } \\
\text { sistemas, proporcionales a } \\
\text { sus capacidades. } \\
\text { - Contemplar los propios } \\
\text { emprendimientos de las } \\
\text { comunidades locales y sa- } \\
\text { beres tradicionales. } \\
\text { - Generar suficientes ingre- } \\
\text { sos para el sostenimiento } \\
\text { del núcleo familiar, garan- } \\
\text { tizar el buen vivir y la so- } \\
\text { beranía alimentaria de las } \\
\text { comunidades locales. } \\
\text { - Siempre deben estar } \\
\text { acompañadas de la actua- } \\
\text { ción integral del Estado y } \\
\text { sus instituciones, para la } \\
\text { garantía de derechos. }\end{array}$ \\
\hline
\end{tabular}

Fuente: elaboración propia con base en Borda et al. (2018), Centro de Estudios para Paz (2019), Corporación Paisajes Rurales, Ministerio de Ambiente y Desarrollo Sostenible y Programa de las Naciones Unidas para el Desarrollo (2018). 


\section{Antecedentes de la ZAP}

Los resultados de los estudios de zonificación ambiental elaborados durante los dos últimos años, que dan lugar a las bases técnicas de zonificación ambiental (BTZA) incorporadas en el PZA, definen las orientaciones para su implementación, enmarcadas en: 1) el Acuerdo de Paz y el Plan Marco de Implementación; 2) instrumentos de planeación vigentes como el Plan Nacional de Desarrollo 2018-2022 y la política Paz con Legalidad, y 3) las competencias establecidas para el MADS por la Ley 99 de 1993, artículo $5^{\circ}$, relacionadas con el ordenamiento ambiental del territorio. El PZA tiene como objetivo desde el ordenamiento ambiental, situar el desarrollo sostenible y equitativo de los territorios, los Planes de Desarrollo con Enfoque Territorial (PDET) y la generación de oportunidades a sus habitantes, mediante la dirección de las decisiones y actuaciones de la institucionalidad nacional y territorial, enfocadas a la estabilización de la frontera agrícola, la protección de las áreas de especial interés ambiental y la generación de alternativas productivas y de vida a la población campesina más afectada por el conflicto (MADS, 2019a).

Uno de sus objetivos específicos es generar un conjunto de acciones que promuevan y faciliten el cierre y estabilización de la frontera agrícola o, incluso, revertir su expansión sobre ecosistemas estratégicos como páramos, humedales y manglares, áreas del Sistema Nacional de Áreas Protegidas (SINAP) y zonas de reserva forestal, principalmente. De otro lado, el PZA pretende generar un uso sostenible y adecuado del territorio, con especial énfasis en la conservación de las AEIA y la reducción de las presiones que afectan la prestación de servicios ecosistémicos. Con relación al desarrollo, el PDET promueve las potencialidades territoriales, en particular las orientadas a la generación de iniciativas productivas y la prestación de servicios ambientales priorizando el rol de la economía campesina y de la mujer. El Acuerdo de Paz propone la democratización del acceso a la tierra y la priorización de procesos de adjudicación y formalización de títulos a poblaciones campesinas, por lo cual el PZA debe orientar territorialmente los procesos de orde- 
namiento social de la propiedad, así como la formalización, restitución y titulación derivados de lo establecido en materia de Reforma Rural Integral. El PZA formula una propuesta orientadora para los actores públicos, privados y comunitarios en las diferentes escalas; en ese sentido, procura contribuir a la construcción de un marco de gobernanza territorial que facilite la coordinación institucional y la actuación territorial convergente, y promueva el empoderamiento de las comunidades rurales a partir de la organización y participación comunitaria en los procesos de planificación y gestión (MADS, 2019a).

Dentro de los principios del PZA podemos mencionar algunos, tales como la transformación estructural del campo, el uso adecuado de la tierra, bienestar y buen vivir, enfoque territorial, integralidad, progresividad y participación efectiva. Con relación a la participación, el PZA señala que incorporará de manera activa y comprometida, en cada nivel de actuación o decisión, las instancias y organizaciones de cada una de las regiones (MADS, 2019a).

El PZA elaborado a la fecha por el Gobierno se encuentra constituido por dos grandes componentes, de acuerdo con lo definido por el MADS (2019):

- Unas bases técnicas ambientales y de participación que desarrollan elementos estructurantes de la planificación ambiental territorial de las subregiones y los municipios en sus PDET, cuyos documentos soportan la formulación del plan y presentan para cada subregión categorías ambientales de uso con sus respectivos lineamientos ambientales para el uso adecuado del suelo y garantía de desarrollo sostenible.

- Un marco estratégico y operativo que establece criterios y orientaciones para la gestión de los asuntos más críticos con respecto a las AEIA, el control de la expansión y estabilización de la frontera agrícola y la puesta en marcha de proyectos productivos en el marco del desarrollo sostenible, y un conjunto integrado de objetivos, acciones 
y responsables para hacer realidad las transformaciones requeridas. A pesar de que la formulación del PZA es liderada por el MADS, su implementación es de carácter interinstitucional, principalmente por la Agencia de Desarrollo Rural (ADR) y autoridades ambientales.

Un primer paso en el desarrollo del PZA ha sido formular las bases técnicas de la zonificación ambiental de los territorios de PDET, los cuales tienen como objetivo priorizar áreas a escala municipal y orientar procesos de ocupación sustentable de los municipios en proceso de posconflicto, de acuerdo con el Decreto 893 de 2017. Por tanto, en dichos municipios se planteó la metodología para la producción de la cartografía a escala 1:100.000, de modo que permitiera la espacialización de la oferta de servicios ecosistémicos, a nivel municipal y su nivel de protección, para con ello priorizar las categorías de conservación necesarias como modelo para la ocupación sustentable de las 17 unidades supramunicipales PDET priorizadas en el posconflicto (Corporación Paisajes Rurales, MADS y PNUD, 2018). Adicionalmente, en vista de lo planteado en el Acuerdo de Paz sobre el desarrollo del componente participativo del PZA, se realizaron algunos pilotos para la construcción de metodologías para la ZAP en diferentes territorios del país (MADS, 2019b).

Un primer ejercicio orientado a la construcción de una ruta metodológica para la ZAP se realizó en el año 2018, producto de la alianza entre el Programa de Naciones Unidas para el Desarrollo (PNUD), el Ministerio de Ambiente y Desarrollo Sostenible (MADS) y la Asociación Nacional de Zonas de Reserva Campesina (ANZORC), teniendo como base las experiencias comunitarias de las zonas de reserva campesina (ZRC) en materia de ordenamiento ambiental y manejo del territorio, en el marco del proyecto "Uso sostenible y conservación de la biodiversidad en ecosistemas secos" del área de desarrollo sostenible del PNUD. La propuesta de ruta metodológica de zonificación ambiental participativa para el posconflicto en las zonas de reserva campesina fue elaborada a partir de los ejercicios realizados en tres ZRC con diferentes procesos de 
constitución legal: ${ }^{1}$ ZRC de Guaviare, ZRC de Perijá-Norte (Cesar)² y la ZRC de Balboa (Cauca). ${ }^{3} \mathrm{Al}$ respecto es válido anotar que la localización de las ZRC en diferentes territorialidades del país y las características disímiles de las comunidades campesinas permitieron la exploración e investigación participativa de herramientas propias de las ciencias sociales y de la planificación actual, como los sistemas de información geográfica (sig), como también generar un proceso de revaloración del conocimiento y de las experiencias vitales de las comunidades, dando como resultado la incorporación del modelo de ocupación en zonas de colonización, como un eje fundamental de la propuesta para la identificación de los principales motores del cambio de uso del suelo de manera histórica y del asentamiento de las comunidades, así como de su configuración actual (Borda et al., 2018).

Una segunda experiencia encaminada a la aplicación de un primer ejercicio de ZAP, es producto de una consultoría realizada por el Centro de Estudios para la Paz (CESPAz), en el marco del contrato suscrito con la Sociedad Alemana para la Cooperación Internacional ( GIZ, Deutsche Gesellschaft für Internationale Zusammenarbeit), relacionado con el ejercicio de formulación de la zonificación ambiental participativa a escala 1:25.000 en los municipios de intervención del proyecto "Ordenamiento territorial orientado al medioambiente en las zonas afectadas por el conflicto en Colombia” AMPAZ-GIZ, en el departamento de Caquetá. Este ejercicio propuso una ruta metodológica de zonificación ambiental participativa para el posconflicto en áreas rurales donde exis-

1 Refiere al origen y estado de las ZRC, la cual surge legalmente mediante una resolución de constitución, conforme al Acuerdo 024 de 1996. Hasta el momento, se encuentran constituidas siete ZRC y seis se encuentran en trámite para adquirir dicha constitución.

2 Esta ZRC está en trámite de constitución.

3 Esta ZRC es de hecho, es decir que, no está constituida legalmente, pero si goza de organización social. Por ello para Anzorc, aunque no esté constituida legalmente, la organización social campesina que de ella emana es legítima y por tanto la reconocen como una autentica ZRC . 
tan comunidades campesinas, que resultó bastante interesante en la medida que arrojó los resultados de la primera zonificación ambiental participativa para los municipios de Albania, Curillo y Valparaíso, lo cual implicaba probar los fundamentos del ejercicio participativo soportados sobre las estructuras organizativas de las comunidades campesinas que contaron a su vez con presencia de otro tipo de actores de comunidades indígenas, lo que enriqueció la aplicación metodológica. Por otro lado, 1) se evidenció la necesidad de incorporar otros escenarios de discusión para la elaboración de acuerdos comunitarios y generar rutas de abordaje de conflictos socioambientales; y 2) la construcción de apuestas productivas sostenibles se dio de manera participativa, así como la generación de propuestas alternativas propias para categorizar el territorio con miras a su ordenamiento (CESPAZ, 2019).

Adicionalmente, se generaron otros escenarios de participación en los que se obtuvo retroalimentación de las bases técnicas de zonificación ambiental, como es el caso de las mesas ambientales subregionales lideradas por la ART y el proyecto piloto de zonificación ambiental participativa en territorios étnicos (MADS, 2019b).

\section{La participación en la ZAP}

Siendo la ZAP un instrumento de planeación que busca posibilitar un diálogo amplio que permita la construcción de apuestas colectivas entre los diferentes actores que tienen injerencia en los territorios rurales, sin embargo, se hace necesario entender la participación como eje fundamental de este proceso, con el fin de comprender de manera integral su alcance, sus oportunidades y limitaciones en el contexto actual del país. Como concepto, la participación puede entenderse como un proceso de carácter eminentemente social, en donde diferentes actores, con intereses, cosmovisiones, necesidades y aspiraciones específicas confluyen y adoptan prácticas intencionales para la consecución de objetivos colectivos, en un contexto de relaciones sociales y de poder (Velásquez y González, 2003; Vallejo y Fuentes, 2005). En este proceso los actores 
sociales buscan intervenir de manera directa en la vida colectiva, para reformar o transformar el sistema social y de políticas públicas en la distribución de los recursos, debatir derechos y deberes de los grupos sociales e incidir en la búsqueda de soluciones a conflictos sociales (Martínez, 2010; 2011).

De acuerdo con Velásquez y González (2003), no necesariamente todas las formas de participación ciudadana se encuentran ligadas o se relacionan con las instituciones del Estado. Es decir, la participación se establece a partir de la acción colectiva alrededor de intereses comunes, vinculando asuntos públicos como la autogestión, que sin la mediación del Estado orientan la solución de problemas.

Velasquéz y González (2003) presentan distintos esquemas de aproximación a la caracterización del grado de influencia e interacción que tienen los ciudadanos sobre las políticas públicas. Dicho grado de interacción e influencia genera distintos planos de profundización de la democracia, aporta de manera diferenciada al incremento en la eficacia y efectividad de las políticas públicas, y promueve distintas ventanas de oportunidad al trámite no violento de conflictos. De acuerdo con lo planteado por Maldonado (2011), se considera necesario delimitar los diferentes niveles de participación para su diferenciación, tal como se observa en la tabla 2. 


\section{Tabla 2. Aproximación a los niveles de la participación en políticas públicas}

\begin{tabular}{|c|c|c|}
\hline $\begin{array}{c}\text { Nivel de } \\
\text { interacción/ } \\
\text { influencia }\end{array}$ & Escenarios & Alcance \\
\hline Información & $\begin{array}{l}\text { La participación se da en } \\
\text { escenarios de entrega de } \\
\text { información a la ciudadanía } \\
\text { sobre un tema específico. }\end{array}$ & $\begin{array}{l}\text { Corresponde fundamentalmente } \\
\text { a ejercicios de socialización } \\
\text { para mantener enterados a los } \\
\text { ciudadanos y sus organizaciones } \\
\text { de las decisiones y la acción de las } \\
\text { instituciones públicas. }\end{array}$ \\
\hline Consulta & $\begin{array}{l}\text { La participación se materializa } \\
\text { mediante escenarios orientados } \\
\text { a la recolección de las } \\
\text { preferencias, percepciones } \\
\text { y consideraciones de la } \\
\text { ciudadanía sobre un tema } \\
\text { espećíico. }\end{array}$ & $\begin{array}{l}\text { Las observaciones de la ciudadanía } \\
\text { no tienen un carácter vinculante. } \\
\text { Además de informar y consultar, } \\
\text { estos espacios suponen una suerte } \\
\text { de retroalimentación por parte de } \\
\text { las instituciones del Estado respecto } \\
\text { a la forma como lo manifestado por } \\
\text { la ciudadanía fue incorporado o no } \\
\text { en la decisión pública. }\end{array}$ \\
\hline Iniciativa & $\begin{array}{l}\text { La participación se expresa } \\
\text { en instancias que permiten } \\
\text { a la ciudadanía proponer la } \\
\text { inclusión de temas en la agenda } \\
\text { pública, o sugerir soluciones a } \\
\text { problemas públicos. }\end{array}$ & $\begin{array}{l}\text { Estos espacios pretenden incentivar } \\
\text { los conocimientos ciudadanos sobre } \\
\text { temas particulares, para valorar } \\
\text { su inclusión en las decisiones } \\
\text { y acciones de las instituciones } \\
\text { públicas. }\end{array}$ \\
\hline Concertación & $\begin{array}{l}\text { La participación se sitúa en un } \\
\text { escenario en el cual, a partir de } \\
\text { una propuesta del Estado, éste y } \\
\text { la ciudadanía generan acuerdos } \\
\text { respecto a la priorización } \\
\text { de acciones sobre un tema } \\
\text { específico. }\end{array}$ & $\begin{array}{l}\text { Las decisiones de estos espacios } \\
\text { tienen un carácter vinculante } \\
\text { y se busca asegurar que las } \\
\text { preferencias y consideraciones de } \\
\text { los ciudadanos se reflejen en las } \\
\text { decisiones y acciones públicas, } \\
\text { pero dentro de un marco de } \\
\text { posibilidades restringido, propuesto } \\
\text { por las instituciones del Estado. }\end{array}$ \\
\hline Decisión & $\begin{array}{l}\text { La participación se expresa en } \\
\text { la posibilidad de generar un } \\
\text { ejercicio deliberativo entre la } \\
\text { ciudadanía y las instituciones } \\
\text { del Estado sobre asuntos de } \\
\text { interés. }\end{array}$ & $\begin{array}{l}\text { En el marco de este tipo de } \\
\text { interacción, las instancias permiten } \\
\text { el intercambio de información, la } \\
\text { construcción de consensos y la } \\
\text { toma de decisiones colectivas. Los } \\
\text { acuerdos producto de estos espacios } \\
\text { son, por lo general, de obligatorio } \\
\text { cumplimiento. Se pretende que las }\end{array}$ \\
\hline
\end{tabular}




\begin{tabular}{|c|c|c|}
\hline $\begin{array}{c}\text { Nivel de } \\
\text { interacción/ } \\
\text { influencia }\end{array}$ & Escenarios & Alcance \\
\hline & & $\begin{array}{l}\text { decisiones y acciones de las } \\
\text { instituciones del Estado reflejen } \\
\text { las preferencias, iniciativas y } \\
\text { consideraciones de la ciudadanía en } \\
\text { los términos derivados del diálogo } \\
\text { sostenido al respecto. }\end{array}$ \\
\hline $\begin{array}{c}\text { Control a la gestión } \\
\text { pública }\end{array}$ & $\begin{array}{l}\text { La participación se expresa } \\
\text { en la posibilidad, por } \\
\text { parte de la ciudadanía, } \\
\text { de destinar esfuerzos } \\
\text { orientados al seguimiento a la } \\
\text { implementación y ejecución } \\
\text { presupuestal de políticas } \\
\text { públicas, y al cumplimiento } \\
\text { de los lineamientos fijados en } \\
\text { herramientas de planeación. }\end{array}$ & $\begin{array}{l}\text { Supone la posibilidad de trasladar } \\
\text { sugerencias de ajustes o cambios } \\
\text { al avance de las acciones } \\
\text { gubernamentales. }\end{array}$ \\
\hline Cogestión & $\begin{array}{l}\text { Como espacio de interacción, } \\
\text { permite la participación de } \\
\text { los ciudadanos en lo público } \\
\text { mediante su vinculación en la } \\
\text { ejecución de planes, programas } \\
\text { y proyectos. }\end{array}$ & $\begin{array}{l}\text { Parte del supuesto del trabajo } \\
\text { conjunto entre ciudadanos e } \\
\text { instituciones, reconociendo el } \\
\text { conocimiento de los primeros } \\
\text { para identificar problemáticas y } \\
\text { encontrar soluciones a las mismas. }\end{array}$ \\
\hline
\end{tabular}

Fuente: elaboración propia con base en Maldonado (2011).

En dicho proceso de participación pueden distinguirse dos importantes elementos: el lenguaje y la interacción. Los dos son fundamentales, por cuanto los actores buscan entenderse sobre una situación que les exige actuar mancomunadamente y coordinar sus acciones, sin embargo, el lenguaje del conjunto de los actores debe surtir una interpretación (Vallejo y Fuentes, 2005), la cual consiste en la construcción de definiciones de una situación susceptible de consenso, para lo cual el lenguaje es determinante. Esta situación pasa necesariamente por el reconocimiento de los diferentes tipos de conocimiento de los actores involucrados y su revaloración (Calle, Giraldo y Piedrahita, 2008), con el fin de viabilizar dicha interpretación y "nivelar” las asimetrías que hagan posible el diálogo de saberes, el cual es entendido por Ishizawa 
(2016) como "la relación mutuamente enriquecedora entre personas y culturas, puestas en colaboración por un destino compartido" (p. 137), donde el conocimiento occidental es solo uno de muchos otros saberes.

Este reconocimiento de los saberes y conocimientos tradicionales pasa, en primera instancia, por resaltar la dominancia histórica y el monopolio ejercido por la ciencia occidental, sobre el cual está basada la técnica institucional y gubernamental en gran parte de los países del mundo incluido Colombia, desconociendo las otras maneras previas y simultáneas en que los seres humanos conocen el mundo y se representan socialmente en la naturaleza (Argueta, 2016). Sin querer ahondar en esta materia, se plantea cómo el giro decolonial del conocimiento (Dussel, 2016) implica entonces abrir un espacio en la validez de la construcción del conocimiento a diferentes tipos de cosmovisiones. En un país como Colombia donde existe gran diversidad cultural y étnica (Calle et al., 2008), se hace indispensable este diálogo de saberes que debe ser, a su vez, intercultural, para que dicha participación sea efectiva y sobre todo incluyente.

El proceso de participación efectiva requiere entonces un proceso de doble vía. Por un lado, la voluntad de los actores institucionales y gubernamentales de garantizar un ambiente que propicie la participación pluralista (Vallejo y Fuentes, 2005), reconociendo los saberes tradicionales y disponiendo de todos los medios para su interpretación equitativa en relación con el conocimiento técnico-institucional, para la construcción de apuestas colectivas de acción que tengan incidencia real en la toma de decisiones en todos los niveles del proceso. Por otro lado, se requieren comunidades interesadas y empoderadas, decididas a trabajar mancomunadamente con los actores institucionales, es decir, una parte participante que sea dinámica y aporte en los procesos de construcción social (Forero, Cardona y Córdoba, 1999), adquiriendo con esto un carácter vinculante.

En razón a lo anterior, la zAP pretende escalar en los niveles de interacción provistos por los actuales marcos normativos, para alcanzar el espacio 
que permita la participación de los ciudadanos en lo público mediante su vinculación en la ejecución de planes, programas y proyectos relacionados con la conservación de los recursos naturales, es decir, "la cogestión de la naturaleza", donde a partir del conocimiento de las comunidades locales se puedan identificar problemáticas y encontrar soluciones relacionadas con el uso y apropiación de la naturaleza, cuidando de que en el proceso se mantenga un trabajo conjunto entre ciudadanos e instituciones (Maldonado, 2011). Esto implica generar un diálogo equilibrado entre los distintos actores, primero, para la construcción de una acción pública orientada a la conservación de la naturaleza creada o apropiada, y segundo, para la elaboración de una propuesta de planificación desde una matriz colectiva, en la puedan materializar su visión del territorio y sus apuestas para el ordenamiento (García, 1976).

La ruta metodológica para la construcción de la ZAP que se describe a continuación, parte en principio de facilitar a los actores locales las herramientas para que ellos puedan ser conscientes de su conocimiento y fortalezcan su gobernanza sobre el territorio. De acuerdo con lo anterior, el propósito de la ZAP como alternativa es generar un sistema de investigación de la realidad, esto es, un sistema de aprendizaje de ella y no tanto un esquema de cómo actuar en la realidad, sino de cómo pensar la realidad y cómo investigarla (Escobar, 2002).

\section{Descripción de la ruta metodológica para la ZAP en zonas de reserva campesina}

La ruta metodológica de zonificación ambiental participativa para el posconflicto elaborada con las comunidades campesinas de las ZRC de Guaviare, Perijá-Norte (César) y Balboa (Cauca), brinda elementos que parecen no ser usuales en la construcción de herramientas o proyectos institucionales. Como resultado de estos ejercicios se determinó que la propuesta de ruta metodológica mencionada se caracteriza por tener los siguientes enfoques: 
- Enfoque territorial: pensar el territorio es pensar en un espacio apropiado por un actor social, es decir, un espacio significado; la apropiación supone productores, actores y consumidores de espacio (Giménez, 2001). En este orden de ideas, la ruta metodológica de la ZAP propone conectar el enfoque de ordenamiento ambiental con el de ordenamiento territorial, y a su vez incorporar la visión del ordenamiento de los colectivos sociales. En la práctica lo que se plantea es confrontar las dos racionalidades en la ordenación del territorio: de un lado la realizada por los colectivos sociales, que sigue dinámicas de apropiación cultural o lógicas basadas en demandas generadas por su necesidad de subsistencia, y de otro lado la establecida desde los marcos normativos (Borda et al., 2018).

- Enfoque de derechos: el enfoque de derechos parte del reconocimiento de las conexiones entre el cuidado de la naturaleza y los derechos humanos, o lo que es igual: “conservación con justicia”. En este entendido se deben considerar las cargas y beneficios que traerán para las comunidades las políticas ambientales que se establezcan en sus territorios, y hacer efectiva la participación, información y concertación de espacios que impulsen a tomar decisiones que no promuevan nuevos conflictos. En este contexto, los talleres realizados en las tres ZRC mostraron que la consecución de objetivos de conservación puede contribuir positivamente a la realización de muchos derechos humanos fundamentales, en particular los relacionados con el derecho al agua, derecho a la soberanía alimentaria, derecho a la tierra, derecho a la vivienda digna, derecho a la participación política, derecho a servicios públicos, derecho a la educación, derecho al territorio, derecho a ejercer las actividades agropecuarias de manera sostenible, derecho a la conservación y cuidado de la naturaleza. Del mismo modo, un régimen seguro de derechos, por ejemplo respecto a la tenencia de la tierra y la participación en la toma de decisiones puede permitir una mejor gestión del medio ambiente (Borda et al., 2018). 
- Enfoque apreciativo: este enfoque se basa en considerar que la imagen positiva construye acciones positivas. Afirma que todos los grupos tienen imágenes positivas de sí mismos, las cuales se fundamentan en sus procesos organizacionales, y que además tienen una tendencia natural a evolucionar hacia las imágenes más positivas mantenidas por sus miembros; sin embargo, estas imágenes se ocultan tras el discurso predominante, que usualmente se caracteriza por el déficit (Pérez, 2017). Así, el enfoque apreciativo parte del reconocimiento de los recursos existentes y de las potencialidades de las comunidades y el contexto para buscar el cambio. Se trata de rescatar lo que está bien y, a partir de ello, construir diferentes realidades, crear e innovar, lo que implica el establecimiento de conversaciones y procesos en los que de forma relatada, a partir de las vivencias y experiencias propias de las personas, se exploran e identifican las capacidades de la organización comunitaria, la motivación y los factores impulsores, las posibilidades de desarrollo y las opciones de acción con vistas al futuro (Agencia de Renovación Territorial [ART] , 2017)

\section{Los momentos e instrumentos de la ruta metodológica} para la ZAP en zonas de reserva campesina

De acuerdo con lo propuesto por Borda et al. (2018), la ruta metodológica desarrollada para la ZAP se construyó participativamente, con la representación de una amplia diversidad de actores, entre ellos la sociedad civil, las instituciones públicas y la academia. ${ }^{4}$ Dicha construcción estuvo facilitada por un equipo técnico que permitió poner en diálogo los tecnicismos institucionales y la visión de territorio de las comunidades que esperan, a partir de un conocimiento experto poder hacer parte de la cogestión de los recursos naturales. Contar con la participación de los ciudadanos en la elaboración de pactos colectivos no solo resulta fundamental para la solución de los problemas más próximos a ellos en

4 La ruta metodológica para la construcción de la ZAP en comunidades campesinas debe precisarse para cada grupo diferencial. 
el nivel local, sino para lograr más eficiencia y eficacia en el diseño e implementación de las políticas públicas (Maldonado, 2011).

La ilustración 1 corresponde al esquema conceptual de la ruta metodológica de zonificación ambiental participativa para el posconflicto en las zonas de reserva campesina. Contiene los elementos determinantes para lograr la planificación de los recursos naturales en el territorio, de forma más eficiente y eficaz.

Ilustración 1. Momentos de la ruta metodológica de la ZAP

-Nivelación del conocimiento técnico institucional y el conocimiento experto de las comunidades.

-Concertación de acuerdos internos.

Momento 1:

alistamiento.

Momento 2:

construcción de la ZAP.
-Diálogo entre las visiones sobre el ordenamiento (comunidades locales con la institucional)

Momento 3: interlocución con otros actores e instituciones

Fuente: adaptada de Borda et al. (2018).

Es importante destacar que dejar de lado toda forma de planeación exclusiva desde lo técnico institucional, fundamentada en una racionalidad instrumental, implica hacer un esfuerzo por el desmonte paradigmático de la causalidad lineal como principal elemento que impide el diálogo entre saberes. Por ello, los momentos de la ruta metodológica de la ZAP no son de carácter lineal sino circular, es decir, no se suceden momento a momento en un orden secuencial estricto, sino de acuerdo 
con su propio desarrollo. Así, por ejemplo, la interlocución entre los actores puede cambiar drásticamente la construcción de la ZAP e incluso exigir la reformulación de todos los presupuestos previstos en el momento de alistamiento: cada momento puede llevar a reformular otro o incluso a que se pueden abordar de forma simultánea.

Esta postura implica una serie de principios de la planeación estratégica situacional como los siguientes: i) Reconocer una realidad en la que coexisten varios actores que tienen capacidades de planeación diferenciadas y por ello hay varias explicaciones de la realidad; ii) No es posible reducir toda la acción humana a comportamientos predecibles: iii) La planificación debe abarcar el problema a tratar con la resistencia de los otros actores que también tienen capacidad de planear; iv) Existen problemas “cuasiestructurados” que se deben a la existencia de incertidumbre, aspecto que dificulta enumerar todas las posibilidades y asignar probabilidades; v) Planificar no es monopolio del Estado. Las distintas fuerzas sociales no solo luchan por sus objetivos, sino que también están en capacidad planear (Matus, 1997).

Bajo este conjunto de principios estructurantes, la propuesta de ruta metodológica se encuentra conformada por los siguientes tres momentos:

1. Momento de alistamiento. En él se planifica el desarrollo de las acciones de gestión, concertación y diagnóstico necesarias para la construcción de la ZAP de la zona de reserva campesina. Implica una serie de actividades de planificación, organización y liderazgo basadas en principios participativos, pues deben integrar los actores ${ }^{5}$ y recursos que contribuyan a satisfacer las necesidades sociales (Guerra, 2014). De otro lado, en este momento se inicia el proceso de interlocución que conduce a reco-

5 Resulta necesario identificar los actores relevantes del territorio y su incidencia en el desarrollo de la ZAP. 
nocer los escenarios y las estructuras organizativas de las comunidades rurales con las que se va a trabajar.

Es en este momento de construcción de la ZAP cuando se identifican los principales hechos históricos de las comunidades campesinas de la zona de reserva. Esta actividad es importante para comprender la construcción de sus territorialidades, su relación con procesos de violencia, actividades económicas -entre ellas las bonanzas económicas-y políticas institucionales de poblamiento que reflejan las conflictividades históricas y emergentes de los territorios de colonización campesina. Para entender los diferentes procesos geográficos del poblamiento se sugiere identificar tres tipos de territorios de la colonización: zonas consolidadas, zonas de transición y zonas de punta de colonización (CNMH, 2017). Esta tipificación se explica con mayor detalle en la tabla 3 del presente artículo.

2. Momento de construcción. Como su nombre lo indica, corresponde a la etapa de construcción de la propuesta ZAP con las comunidades campesinas. Parte de la identificación comunitaria de áreas ambientales de manejo especial, sistemas productivos y conflictos socioambientales, luego se elaboran las medidas comunitarias de manejo y las acciones en el contexto de la ZAP. Este ejercicio requiere haber reconocido en la fase de alistamiento las estructuras organizativas y participativas de las comunidades rurales, con el fin de que sean los representantes legitimidad por estas quienes asistan y participen en la construcción de la propuesta. Seguidamente estos líderes, con ayuda del equipo técnico, deben bajar la información a su comunidad para conjuntamente hacer los ajustes y recomendaciones necesarias. Finalmente, en un escenario definido por las mismas comunidades se aprueba la propuesta mediante el mecanismo que ellos mismos propongan.

3. Momento de interlocución con otros actores e instituciones. La interlocución busca concertar la propuesta de ZAP con otros actores claves. Inicialmente, se socializa la propuesta construida por los actores locales con la institucionalidad agraria y ambiental, así como con la art y se ex- 
ponen los resultados de la comparación con la propuesta institucional. A continuación, se conforma de una mesa de concertación en la cual: i) las organizaciones comunitarias encuentren respuesta a sus demandas y expectativas, y ii) se articulen los intereses de otros actores y la institucionalidad avance en el cumplimiento de su misión. Finalmente, desde la mesa de concertación se impulsa la construcción de acuerdos inicialmente transitorios y luego definitivos.

Un aspecto de gran relevancia en el planteamiento de la ruta metodológica es el análisis del modelo de ocupación del territorio, dado que este es vital para el entendimiento de las dinámicas territoriales, su colonización y asentamiento. Para dicho análisis se recurre a la identificación del proceso histórico de ocupación, a partir de líneas de tiempo direccionadas sobre las temáticas que generan mayores transformaciones y movilidad de los actores en el territorio: bonanzas económicas, hechos de violencia y establecimiento de infraestructura, especialmente la vial. Adicionalmente, se caracteriza el comportamiento de la colonización por medio de cartografía social. Según González (1984), la configuración geográfica producto de la colonización diferencia tres tipos de zonas:

Las zonas consolidadas son aquellas que están integradas económicamente a la economía regional y tienen acceso a bienes públicos rurales. Las zonas de transición son aquellas a las que se ha integrado parcialmente la economía regional, donde hay algunos bienes públicos rurales, carreteras (generalmente en mal estado) y una fonda que sirve de mercado en la región. Por último, las zonas de punta de colonización son aquellas que no están articuladas a la economía regional, en las que los colonos abren sus fundos y adquieren los bienes y servicios que necesitan en las zonas de transición. (Cit. por CNMH, 2017, p. 33). [Cursivas en el original].

Esta zonificación resulta de gran ayuda para entender de manera holística la forma como se han configurado los territorios de colonización en el país, zonas que además se desarrollan sin presencia activa del Estado, sino mediante fuertes lazos de solidaridad sobre todo en las zonas de 
transición y de punta de colonización, donde las condiciones son mucho más adversas y es común el trabajo comunitario a mano vuelta, ${ }^{6}$ llevados también de forma histórica a estos territorios por bonanzas de determinados cultivos, explotación de maderas, economías ilegales, o como formas de colonización que obedecen a los desplazamientos originados por el conflicto armado (Fajardo, 2002; LeGrand, 1988), entre otras, en la ampliación de la frontera agropecuaria. Sin embargo, para aterrizar dichas zonas, en la práctica se requiere seleccionar las variables de mayor incidencia en estos procesos para facilitar su adecuada identificación.

Para dar mayor alcance a estas zonas se propusieron algunas variables que pueden caracterizar cada uno de los territorios de colonización. Aunque se construyeron para una tipología general de territorio, pueden ajustarse de forma participativa con los actores involucrados, de acuerdo con sus propias características.

\section{Tabla 3. Variables para la caracterización de las categorías de la co- lonización}

\begin{tabular}{|c|c|c|}
\hline Zona consolidada & Zona intermedia & Zona punta \\
\hline $\begin{array}{l}\text { - Comercialización regional y } \\
\text { nacional sin o con poco des- } \\
\text { plazamiento. } \\
\text { - Acceso a variedad de pro- } \\
\text { ductos de otras zonas. }\end{array}$ & $\begin{array}{l}\text { - Comercialización local y } \\
\text { regional máxima, desplaza- } \\
\text { mientos (rango intermedio). } \\
\text { - Variedad y disponibilidad } \\
\text { limitada de productos de } \\
\text { otras zonas. }\end{array}$ & $\begin{array}{l}\text { - Autoconsumo, trueque en- } \\
\text { tre vecinos. } \\
\text { - Poco o nulo acceso a pro- } \\
\text { ductos de otras zonas, pe- } \\
\text { queñas tiendas o taguaras. } \\
\text { - Economías ilegales (cultivos } \\
\text { de uso ilícito, minería y ex- } \\
\text { tracción de madera). }\end{array}$ \\
\hline $\begin{array}{l}\text { Existen centros poblados } \\
\text { importantes, vías primarias. }\end{array}$ & $\begin{array}{l}\text { Existen centros poblados } \\
\text { pequeños y vías secundarias. }\end{array}$ & $\begin{array}{l}\text { No se evidencian centros } \\
\text { poblados grandes y vías } \\
\text { terciarias o sin vías. }\end{array}$ \\
\hline
\end{tabular}

6 Se refiere a todas las formas de trabajo comunitario y familiar, con o sin reciprocidad, que desarrollan comunidades étnicas, mestizas o campesinas bajo lazos de cooperatividad y solidaridad (Martinez, 2012). 


\begin{tabular}{|l|l|l|}
\hline \multicolumn{1}{|c|}{ Zona consolidada } & \multicolumn{1}{c|}{ Zona intermedia } & \multicolumn{1}{c|}{ Zona punta } \\
\hline $\begin{array}{l}\text { Fuentes de Energía: } \\
\text { interconexión eléctrica. }\end{array}$ & $\begin{array}{l}\text { Fuentes de Energía: } \\
\text { interconexión eléctrica parcial, } \\
\text { otras fuentes, plantas (por } \\
\text { zonas). } \\
\text { Cobertura: } 40-60 \% .\end{array}$ & $\begin{array}{l}\text { Fuentes de Energía: no } \\
\text { interconexión, plantas } \\
\text { pequeñas, dinamos, paneles } \\
\text { solares (por finca). } \\
\text { Cobertura: 0-10\% }\end{array}$ \\
\hline $\begin{array}{l}\text { Intervención de los } \\
\text { ecosistemas. } \\
90-100 \% \text { intervenido }\end{array}$ & $\begin{array}{l}\text { Intervención de los } \\
\text { ecosistemas. } \\
90-70 \% \text { intervenido. }\end{array}$ & $\begin{array}{l}\text { ecosistemas, focos activos de } \\
\text { deforestación. } \\
<70 \% \text { intervenido } \\
\text { Existe cacería y } \\
\text { aprovechamiento. }\end{array}$ \\
\hline
\end{tabular}

Fuente: elaboración propia con base en Borda et al. (2018) y CNMH (2017).

Finalmente, en este punto es importante resaltar otro componente propuesto por la ruta metodológica en mención, referente a la aproximación histórica de dicho modelo de ocupación: la importancia de encontrar los drivers o generadores del cambio de uso del suelo en el tiempo y la movilización de la población, con el fin de determinar con mayor detalle los hitos que han desencadenado la expansión-relocalización de las dinámicas humanas en el territorio (Borda et al., 2018), a través de instrumentos de las ciencias sociales, como la línea de tiempo y la cartografía social.

\section{Procesos de planificación en relación con la ZAP}

A pesar de que la planificación territorial ha sido una necesidad imperante de los Estados a través de la historia para organizar la ocupación y uso de los espacios apropiados por estos, lo que se evidencia es la ampliación de las desigualdades, la precarización de las condiciones de las zonas aisladas y la ampliación de la brecha centro-periferia, dado que en el esfuerzo por ejercer el poder y gobernar la planificación se concentró en los polos de desarrollo (Boisier, 1994), es decir, en las grandes urbes del país como Bogotá, Cali, Medellín y Popayán, con énfasis en metodologías de planificación eminentemente urbanas im- 
portadas principalmente de Europa (Renginfo, 2003). Esta política de planificación dejó por fuera de los planes de desarrollo al resto de los territorios del país, en especial las zonas rurales, situación que no ha podido ser revertida (Agudelo, 2006), negándosele de igual manera a estos territorios la posibilidad de un desarrollo territorial endógeno de acuerdo con sus contextos locales específicos.

Otro aspecto importante de considerar desde una mirada crítica de los procesos de planificación de ordenamiento territorial y ambiental en el país es la ausencia de participación de los diferentes actores locales, limitando el diálogo social y la concertación de apuestas territoriales, por cuanto no se garantizan condiciones y canales suficientes para decidir acciones colectivas (Forero, 2000), así dichos procesos sean subordinados a nivel de la entidad territorial. En consecuencia, se fomentan enfoques de arriba hacia abajo que fracasan en la práctica debido a su falta de contexto territorial y social (FAO, 2005); los instrumentos técnicos de ordenamiento carecen de legitimidad social suficiente, responden a enfoques tecnocráticos que resaltan ciertas áreas del conocimiento o presentan capítulos no conectados y aislados de diagnóstico que imposibilitan obtener conclusiones e hipótesis (Espinosa, 1999; 2002).

El ordenamiento con énfasis ambiental desde su origen y desarrollo ha tenido una marcada orientación de preservación, fundamentada en una visión meramente ecológica y proteccionista o de conservación estricta, en razón a la supuesta intangibilidad de las áreas (islas) prístinas. En virtud de lo anterior, se ha desconocido el contexto social, económico y cultural; se ha excluido al ser humano de estas zonas argumentando su "fragilidad"; y se ha pasado por encima de los intereses de las poblaciones locales (Toledo, 2005). Al no existir políticas que impulsen el desarrollo local y regional, dicho desconocimiento impide visibilizar las relaciones simbólicas y de apropiación que han generado las comunidades locales, sin tener en cuenta que la diversidad cultural es un reflejo de la biodiversidad (Noguera, 2007) y de esta forma atender los problemas culturales que tienen relación directa con la búsqueda de 
soluciones a los conflictos ambientales existentes en las zonas rurales del país (Ángel, 1995). Por consiguiente, la institucionalidad del Estado y la academia deben iniciar un proceso de reflexión, enfocado en el reconocimiento de un ordenamiento territorial surgido desde los mismos colectivos sociales. Este ordenamiento realizado por las propias comunidades se ha denominado diseño autónomo, en tanto son los mismo habitantes quienes definen su realidad; esto quiere decir, en términos filosóficos, que siempre se la debe ver como agente de su propio entendimiento, como practicante de su propio saber, ese es un principio básico, político, epistemológico, que es violentado por la planificación convencional (Escobar, 2002).

El aumento en la declaratoria y ampliación de las áreas protegidas en el país se ha fundamentado en la idea de que la protección de la naturaleza es una meta alcanzable solo en ausencia de personas (D’amico, 2015), lo cual implica ubicar lo humano fuera de la naturaleza como un elemento central de la reproducción de este modelo de conservación (D’amico, 2015). Sin embargo, son las comunidades campesinas, quienes se ven obligadas, presionadas e incluso incentivadas a colonizar dichos espacios en el marco del conflicto (Fajardo, 2012), situación que ha ocasionado su estigmatización y de igual forma ha generado una escisión mucho más marcada en la intervención de los territorios, en la que se separan irreconciliablemente las áreas dedicadas a la preservación ambiental y las áreas "productivas" (Toledo, 2005). Este enfoque excluyente, de acuerdo con Lele, Wilshusen, Brockington y Seidler (2010), puede ocasionar tres tipos de impactos asociados sobre las comunidades que habitan las áreas protegidas o colindan con ellas: i) desplazamiento económico por las condiciones impuestas sobre el uso del suelo en estas zonas; ii) desplazamiento cultural por la restricción en el acceso a lugares con valores simbólicos y culturales; y iii) desplazamiento forzado, ocasionado por estrategias de militarización y criminalización de las comunidades, promoviendo nuevos conflictos socioambientales y rompiendo los lazos sociedad-naturaleza (Toledo, 2013), invisibilizando a sus habitantes y generando nuevas violencias sobre 
las comunidades locales, especialmente donde el flagelo de la guerra ha arreciado con mayor intensidad, revictimizándolas, esta vez desde la intervención estatal e impidiendo la construcción de Paz.

Son bastante variadas las corrientes interpretativas del ordenamiento territorial y ambiental; de igual manera son diversos los análisis que se alejan de una serie de postulados y presupuestos teóricos rígidos contrarios a una realidad que sobrepasa cualquier esquematización, lo que hace que las técnicas de ordenamiento territorial y ambiental predominantes se limiten solo a la organización espacial y técnico-normativa (Bernal, 1998). En esta circunstancia la discusión sobre los diferentes énfasis del ordenamiento se limita muchas veces a los elementos técnicos materializados en la zonificación, como por ejemplo la escala, detalle y tratamiento de la información cartográfica, más que al diálogo, la construcción de conocimiento y la concertación con los diferentes actores para la generación conjunta de una visión territorial a futuro (Vieco, 2000). En razón a todo lo expuesto, el avance del país en procesos de planificación se considera bastante tardío, a lo cual se suma la inestabilidad y la escasez de recursos económicos suficientes para su implementación (Renginfo, 2003), factores que no han permitido la materialización del desarrollo ambiental, económico y social esperado de estos procesos.

De acuerdo con lo anterior y las características ya tratadas sobre la ZAP en razón al ordenamiento y planificación territorial convencional realizado en el país, es posible establecer el siguiente paralelo respecto a sus potencialidades como herramienta para la planificación territorial ambiental. 


\section{Tabla 4. Paralelo entre las formas de planificación territorial ambiental convencional y la ZAP}

\begin{tabular}{|c|c|}
\hline $\begin{array}{l}\text { Planificación territorial y } \\
\text { ambiental convencional }\end{array}$ & ZAP \\
\hline $\begin{array}{l}\text { Propicia bajos o nulos niveles de participación } \\
\text { y por ende de legitimidad. }\end{array}$ & $\begin{array}{l}\text { Propicia altos niveles de participación } \\
\text { amplia y efectiva, con lo cual se fortalece el } \\
\text { empoderamiento de las comunidades. }\end{array}$ \\
\hline $\begin{array}{l}\text { Prevalece el conocimiento tecnocrático y } \\
\text { segmentado para la toma de decisiones. }\end{array}$ & $\begin{array}{l}\text { Genera revaloración de conocimientos } \\
\text { locales tradicionales, diálogo de saberes y } \\
\text { transdisciplinariedad para la construcción } \\
\text { colectiva. }\end{array}$ \\
\hline $\begin{array}{l}\text { Reproduce paradigmas de conservación } \\
\text { estricta, prístina y proteccionista. }\end{array}$ & $\begin{array}{l}\text { Promueve paradigmas alternativos de } \\
\text { conservación ambiental, manejos comunitarios } \\
\text { y cogestión de los socioecosistemas. }\end{array}$ \\
\hline $\begin{array}{l}\text { Genera divisiones marcadas entre las áreas } \\
\text { ambientales y agropecuarias. }\end{array}$ & $\begin{array}{l}\text { Genera visiones holísticas e integrales del } \\
\text { territorio que reconocen al ser humano } \\
\text { como parte de la biodiversidad, así como las } \\
\text { interconexiones existentes sin separarlas. }\end{array}$ \\
\hline $\begin{array}{l}\text { Énfasis en el ordenamiento urbano sobre el } \\
\text { rural. }\end{array}$ & $\begin{array}{l}\text { Su enfoque y forma de construcción atiende } \\
\text { mayormente a las dinámicas del suelo rural. }\end{array}$ \\
\hline $\begin{array}{l}\text { Su construcción generalmente se realiza } \\
\text { de arriba hacia abajo, es decir, desde las } \\
\text { instituciones del Estado hacia los territorios. }\end{array}$ & $\begin{array}{l}\text { Permite invertir los procesos de planificación } \\
\text { de abajo hacia arriba, es decir, desde } \\
\text { las comunidades locales hacia el nivel } \\
\text { institucional. }\end{array}$ \\
\hline $\begin{array}{l}\text { Contempla generalmente metodologías } \\
\text { estándar, sin analizar los modelos de ocupación } \\
\text { de cada territorio. }\end{array}$ & $\begin{array}{l}\text { Las apuestas metodológicas permiten } \\
\text { flexibilizar e incorporar elementos producto de } \\
\text { las condiciones específicas de cada territorio, } \\
\text { analizando su modelo de ocupación. }\end{array}$ \\
\hline Marco normativo extenso y robusto. & $\begin{array}{l}\text { Marco normativo débilmente representado y en } \\
\text { construcción en la actualidad. }\end{array}$ \\
\hline
\end{tabular}

Fuente: elaboración propia con base en Bernal (1998), Renginfo (2003), Toledo (2005), Borda et al. (2018).

Pese a las grandes potencialidades de la ZAP previamente expuestas, a la identificación de las AEIA ya referidas, al análisis planteado y lo expuesto por Carrizosa, Fajardo, Rudas y Ruiz (2014), Rodríguez, Rodríguez y Du- 
rán (2017), en el marco de la implementación del Acuerdo de Paz y del contexto actual del país este proceso presenta importantes retos, a saber:

- La movilidad de la población, emigración y migración voluntaria por falta de oportunidades y carencias socioeconómicas, así como evidentes riesgos de desplazamientos forzosos y frustración del retorno de familias por recrudecimiento del conflicto armado, lo cual desestabiliza la estructura territorial dificultando la consolidación de procesos de gobernanza ambiental sobre estas zonas.

- La ausencia de un marco regulatorio adecuado, con recursos que permitan implementar la ZAP en cada territorio.

- La falta de capacidad de las instituciones del Estado, especialmente del sector ambiental y agrario, para interiorizar nuevos enfoques participativos.

- Las intenciones de otros sectores como el minero-energético, en cuanto a determinar el uso del suelo para la explotación y aprovechamiento de este tipo de recursos.

- El restablecimiento de los lazos de confianza de los actores locales con la institucionalidad ambiental y local, los cuales se han perdido debido a la falta de apoyo, victimización, hechos de corrupción y clientelismo, situación que dificulta la aplicación justa y equitativa de la normatividad ambiental, la gestión ambiental de estas zonas, el abordaje de conflictos socio-ambientales y la actuación conjunta.

- El incremento de fenómenos de concentración y acaparamiento de tierras constituye un importante riesgo para las AEIA en materia de acceso y democratización de su uso. Además, el control por parte de algunos actores imposibilita su gobernanza colectiva, y se ha demostrado que los grandes propietarios tienden a generar mayor 
impacto sobre estas áreas, sin importar el beneficio colectivo que proveen.

- La aparición de nuevas formas de violencia y de grupos armados emergentes en el posacuerdo pone en riesgo la seguridad y movilidad de las comunidades locales, amenazando los procesos de empoderamiento ambiental y los liderazgos para conservar las AEIA.

- El incumplimiento de los PNIS y demás puntos del Acuerdo de Paz, en sumatoria con lo señalado en el punto anterior y la posibilidad latente de reactivación de las aspersiones con glifosato, pueden generar un nuevo auge y proliferación de economías ilegales como el cultivo de coca y la minería ilegal, amenazando seriamente la conservación de las AEIA.

- La identificación de las AEIA puede motivar al sector ambiental a la declaratoria inconsulta de nuevas áreas protegidas o a la militarización de estas zonas, situación que agravaría y profundizaría los conflictos socioambientales en el territorio, por lo tanto, esta alternativa de gestión no se considera apropiada; sin embargo, siempre hay un riesgo en materia de propuestas de manejo ambiental.

\section{Conclusiones}

El cierre de la frontera agrícola y protección de zonas de reserva (punto 1.1.10 del Acuerdo de Paz) representa para el país una gran oportunidad respecto a la zonificación ambiental participativa, como alternativa para la construcción de apuestas territoriales y de planificación de uso y apropiación de la naturaleza; la búsqueda de soluciones más adecuadas y aterrizadas tanto en los conflictos socioambientales como en las causas históricas del conflicto armado que aquejan las zonas rurales; y la identificación de áreas de especial interés ambiental y de alternativas equilibradas para las comunidades locales. 
Los procesos de planificación y ordenamiento ambiental territorial no han materializado sus objetivos de desarrollo social y económico ni de conservación ambiental, a pesar de existir numerosos tipos de instrumentos. Esto se debe: i) a que no contemplan el contexto territorial ni el modelo de ocupación del cual se derivan los conflictos históricos por el uso y ocupación de la tierra y la naturaleza; y 2) a que su concepción se basa principalmente en desarrollos tecnocráticos de arriba hacia abajo, con nula o poca articulación y participación de los actores locales, enfoque que ha profundizado aún más la brecha entre las zonas urbanas y rurales, ha relegado la ruralidad y los actores locales, ha acrecentado los conflictos socioambientales y ha imposibilitado la aplicación de un verdadero enfoque territorial con justicia social y ambiental.

La propuesta metodológica para la construcción de la ZAP en zonas de reserva campesina, presentada en este artículo, parte del reconocimiento y revaloración de los aprendizajes y saberes tradicionales sobre el manejo y uso de la naturaleza, así como de las formas de organización y toma de decisiones de las comunidades locales sobre su territorio, es decir, de un enfoque apreciativo en el cual se invierte el proceso de planificación (de abajo hacia arriba); se pone a un mismo nivel y en un mismo lenguaje la construcción de conocimiento de las comunidades; se vinculan a los actores institucionales y académicos para fomentar un diálogo amplio e incluyente con participación activa e incidente de las comunidades locales; se estimula la generación de pactos y acuerdos que conlleven la implementación de apuestas adecuadas para la resolución de los conflictos socioambientales; y se fortalece la gobernanza ambiental y el empoderamiento local para la construcción de una paz estable y duradera.

El análisis del modelo de ocupación del territorio utilizando los momentos o fases de la colonización permite aproximarse a la explicación de las conflictividades y las interrelaciones actuales entre los diferentes actores del territorio, lo cual es de vital importancia para el proceso de planificación y construcción de la ZAP. De igual manera, la integración de instru- 
mentos participativos con herramientas técnico-científicas hace posible la nivelación y "traducción” de los lenguajes para favorecer el diálogo de saberes entre los actores subalternos y los demás participantes.

La identificación participativa de las AEIA y su caracterización, en el marco de la propuesta metodológica de la ZAP, permite construir apuestas de conservación ambiental integrando valores culturales y tradicionales, así como promover nuevos paradigmas de conservación más incluyentes y menos proteccionistas, que reconozcan y revaloren procesos de gobernanza ambiental y de aprovechamiento sustentable de la naturaleza desde las comunidades locales.

La ruta metodológica para la ZAP en zonas de reserva campesina contiene elementos innovadores frente al abordaje de la planificación territorial ambiental, que representan un gran potencial para la construcción de propuestas colectivas de conservación y gobernanza ambiental, y permiten caracterizar y evidenciar aspectos del modelo de ocupación del territorio que son determinantes para la resolución de los conflictos socioambientales, la estabilización de la población y la búsqueda de alternativas equilibradas para las comunidades locales.

\section{Referencias}

Acuerdo de Paz. (2016). http://www.altocomisionadoparalapaz.gov.co/ procesos-y-conversaciones/Paginas/Texto-completo-del-Acuerdo-Final-para-la-Terminacion-del-conflicto.aspx. Obtenido de http://www.altocomisionadoparalapaz.gov.co/procesos-y-conversaciones/Paginas/Textocompleto-del-Acuerdo-Final-para-la-Terminacion-del-conflicto.aspx

Agencia de Renovación Territorial ART. (2017). El diálogo en los núcleos veredales. Caja de herramientas metodológicas para facilitadores(as) de diálogo en el marco de los Programas de Desarrollo con Enfoque Territorial (PDET. Bogotá: Agencia de Renovación Territorial/Programa de Apoyo a la Construcción de la Paz en Colombia/ Deutsche Gesellschaft für Internationale Zusammenarbeit. 
Agudelo, L. (2006). La Ruralidad en el Ordenamiento Territorial en Colombia. Congreso ACIUR. Bogotá: UnAL.

Ángel, A. (1995). La Fragilidad Ambiental de la Cultura. Bogotá: UnAL.

ANZORC, MADS \& PNUD. (s.f.).

Argueta, A. (2016). El diálogo de saberes, una utopía realista. En F. Delgado, \& S. Rist, Ciencias, diálogo de saberes y transdisciplinariedad (págs. 119-128). La Paz, Bolivia: Plural editores.

Bernal, C. (1998). Otra mirada al ordenamiento territorial. Perspectiva Geográfica, 20-30.

Boisier, S. (1994). Post-modernismo territorial y globalización: regiones pivotales y regiones virtuales. Ciudad y territorio. Estudios Territoriales vol. 2, $N^{\circ} 102$.

Borda, S., Giraldo, J., Sanchez, S., \& Torres, S. (2018). Guía metodológica para la zonificacion ambiental participativa para el posconflicto en las zonas de reserva campesina. Bogotá, Colombia: Anzorc-PNuD.

Calle, Z., Giraldo, E., \& Piedrahita, L. (2008). Diálogo de saberes para la restauración ecológica de bosques: el papel de los niños y jóvenes investigadores. Revista Estudios Sociales Comparativos, 68-85.

Carrizosa, J., Fajardo, D., Rudas, G., \& Ruiz, J. P. (2014). Consideraciones ambientales para la construcción de una paz estable, duradera y sostenible en Colombia. Bogotá: PNUD, GIZ.

Cespaz. (2019). Proyecto Desarrollo o complementación de elementos del Plan de Zonificación Ambiental elaborado por el Ministerio de Ambiente y Desarrollo Sostenible, en su componente de participación. Bogotá: Centro de Estudios para la Paz.

Chaux, G. (2007). El ordenamiento territorial una herramienta para la gestión del riesgo. Bogota: IDRC.

Cifuentes, A., Contreras, D., \& Fernández, L. R. (2015). Ordenamiento territorial como instrumento, para la zonificación ambiental a traves de la Estructura Ecologica Principal, como apoyo a la formulación de los POTs y los POMCAS en Colombia. Revista de Tecnología : Journal of Technology : Volumen 14 ínermero 2, 49-76. 
CNMH. (2017). la tierra no basta Colonización, baldios, conflicto y organizaciones sociales en el Caquetá. Bogotá, Colombia.: Centro Nacional de Memoria Histórica.

Corporación Paisajes Rurales, MADS \& PNUD. (2018). Medtodología para la definición de las bases técnicas para la zonificación ambiental en unidades suparmunicipales pdtes priorizadas en el Posconflicto. Bogotá: Corporación Paisajes Rurales, Programa de las Nacioanes Unidas para el Desarrollo y Ministerio de Ambiente y Desarrollosostenible.

D’amico, M. P. (2015). Debates sobre conservación y áreas naturales protegidas: paradigmas consolidados y nuevos horizontes. Revista Latinoamericana de Estudios Socioambientales No 18, 208-226.

Dominguez, S. (2008). Zonificación ambiental para el ordenamiento territorial de la subcuenca bimunicipal del río Aguas Calientes, Nicaragua. Turrialba, Costarica: CATIE.

Durán, H., Rodríguez, C., \& Rodríguez, D. (2017). La Paz Ambiental retos y propuestas para el posacuerdo. Bogotá: Dejusticia.

Dussel, E. (2016). Filosofías del sur descolonización y transmodernidad. Ciudad de México: Akal.

Escobar, A. (2002). Globalización, Desarrollo y Modernidad. Medellín: Corporación Región. Planeación, Participación y Desarrollo.

Espinosa, O. (1999). ¿Crisis ecológica? El que hacer de las ciencias sociales en lo ambiental. En L. Cucurrella, Antropología en el Ciberespacio. Quito, Ecuador: Centro Cultural Abya Yala.

Espinosa, O. (2002). Comentarios para una crítca a los Planes de Ordenamiento Territorial en Colombia. Territorios 8. 128., 127-166.

Estrada, J., Ordoñez, F., \& Sanchez, P. (2013). El proceso de las zonas de reserva campesina, trayectoria histórica y configuraciones territoriales. En E. Jairo, Territorios Campesino la experiencia de las zonas de reserva campesina (págs. 25-67). Bogotá: Universidad Nacional de Colombia.

Fajardo, D. (2002). Para sembrar la paz hay que aflojar la tierra. Bogotá, Colombia: IDEA - Universidad Nacional de Colombia.

Fajardo, D. (2012). Estudio Sobre Los Orígenes Del Conflicto Social Armado, Razones De Su Persistencia Y Sus Efectos Más Profundos En La Sociedad Colombiana. Bogotá: Espacio Crítico. 
FAO. (2005). Un enfoque para el desarrollo rural: Desarrollo Territorial Participativo y Negociado.

Forero, C. (2000). Descentralización y Ordenamiento Territorial. En J. Vieco, C. Franky, y J. Echeverri, Territorialidad Indígena y Ordenamiento en la Amazonía (págs. 139-151). Bogotá: UNIBIBLOS.

Forero, C., Cardona, G., \& Córdoba, C. (1999). Planeación Participativa, "Estrategia de paz”. Bogota: Concejo Nacional de Planeación.

García, J. (1976). Antropología del Territorio. Madrid: Taller de Ediciones Josefina Betancor.

Giménez, G. (2001). Cultura, territorio y Migraciones. Aproximaciones teóricas. Revista Alteridades. Vol. 11. Julio-Diciembre, Universidad Autónoma Metropolitana-Iztapalapaga. Distrito Federal Mexico.

Gobierno Nacional de Colombia y FARC-EP. (2016). Acuerdo Final para la Terminación del Conflicto y la Construcción de una Paz Estable y Duradera. La Habana, Cuba. 12 de noviembre de 2016: Gobierno Nacional de Colombia.

Guerra, K. (2014). Propuesta de una tecnología para la gestión de proyectos de innovación en el sistema territorial de ciencia e innovación en Cuba. Revista Cubana de información en Ciencias de la Salud, Habana, cuba.

Ishizawa, J. (2016). Comunidades epistémicas para el diálogo de saberes. En F. Delgado, y S. Rist, Ciencias, diálogo de saberes y transdisciplinariedad (págs. 137-165). La Paz, Bolivia: Plural editores.

Jiménez, W. (1995). Zonificación agroecológica de la región de Acosta. Avances de Investigación. San José, Costa Rica: CEDECO.

LeGrand, C. (1988). Colonización y protesta campesina en Colombia (18501950). Bogotá, Colombia: Universidad Nacional de Colombia.

Lele, S., Wilshusen, P., Brockington, D., y Seidler, R. y. (2010). Beyond exclusion: Alternative approach to biodiversity conservation in the developing tropics. . Current Opinion in Environmental Sustainability, 2, 94-100.

MADS. (2019a). Plan de Zonificación Ambiental objeto del punto 1.1.10 del acuerdo final de Paz. Bogotá: Ministerio de Ambiente y Desarrollo Sostenible. 
MADS. (2019b). Plan de Zonificación Ambiental. Presentación Plan de Zonificación Ambiental. Bogotá.

Maldonado, C. (2011). Participación ciudadana en la construcción de la paz territorial en Colombia. Participación ciudadana en la construcción de la paz territorial en Colombia. Bogotá: Desarrollo y Paz territorial.

Martinez, J. (2012). Las cooperativas en América Latina: visión histórica general y comentario de algunos países tipo. CIRIEC-ESPAÑA No EXTRAORDINARIO 43, 145-172.

Martinez, M. (2010). The Citizen Participation of Urban Movements in Spatial Planning: A Comparison between Vigo and Porto. International Journal of Urban and Regional Research Vol 35, 147-171.

Martinez, M. (2011). Dimensiones múltiples de la participación ciudadana en la planifi cación espacial. Reiss 133, 21-42.

Matus, C. (1997). Guía de análisis teórico, Seminario de Gobierno y Planificación, Método. Caracas, Venezuela: Fundación Altadir.

Montoya, G. (2011). La zonificación ambiental en la cuenca hidrográfica media del rio negro. Salamanca, España: Universidad de Salamanca.

Noguera de Echeverri, A. P. (2007). Complejidad ambiental: propuestas éticas emergentes del pensamiento ambiental latino-americano . Medellin, Colombia: UNAL.

Ortiz, A. (2013). Relación entre la objetividad y la subjetividad en las ciencias humanas y sociales. Revista Colombiana de Filosofía de la Ciencia, vol. 13, núm. 27, 85-106.

Pérez, T. (2017). El enfoque apreciativo, valiosa herramienta para construir cultura de paz. Revista de la Universidad de la Salle, 137-158.

Ponce, R. (1998). Zonificación Ecológica - Económica: Una Propuesta Metodológica para la Amazonia. Caracas, Venezuela: Cooperación Amazónica.

Raffestin, C. (2011). Por uma geografia do poder. Sao Paulo: Ática.

Renginfo, J. (2003). Evolución y establecimiento de la planificación municipal en Colombia. Revista De Investigación Geográfica De La Universidad de Nariño, 27-39. 
Solano, F. (2017). Propuesta de zonificación ambiental del corredor biológico interurbano río María Aguilar, Costa Rica. Revista de Ciencias Ambientales (Trop J Environ Sci) Vol 51(1), 33-50.

Toledo, V. (2005). Repensar la Conservación:záreas naturales protegidas o estrategia bioregional?. Gaceta Ecológica 77, 67-83.

Toledo, V. (2013). El metabolismo social: una nueva teoría socioecológica. Relaciones 136, otoño, 41.71.

Vallejo, L., y Fuentes, H. (2005). De la planeación normativa a la participativa en Colombia: una aproximación al caso del manejo de los recursos ambientales. Tunja, Colombia: Apuntes cenes.

Velásquez, F., y González, E. (2003). ¿Qué ha pasado con la Participación Ciudadana en Colombia? Bogotá, Colombia: Fundación Corono.

Velasquéz, F., y González, E. (2003). Que pasa con la participación en Colombia? Bogotá: Fundación Corona.

Vieco, J. (2000). Ordenamiento Territorial en el Amazonas: Realidades y Conflictos. En J. Vieco, C. Franky, y J. Echeverri, Territorialidad Indígena y Ordenamiento en la Amazonía (págs. 136-151). Leticia: unibiblos. 